\title{
Interactive Multimedia Teaching of Digital Signal Processors
}

\author{
S. L. TORAL, ${ }^{1}$ F. BARRERO, ${ }^{1}$ M. R. MARTÍNEZ-TORRES, ${ }^{2}$ S. GALLARDO ${ }^{1}$ \\ ${ }^{1}$ E.S. Ingenieros, University of Seville, Seville, Spain \\ ${ }^{2}$ E.U. Estudios Empresariales, University of Serille, Seville, Spain
}

\begin{abstract}
This article shows a novel approach to Digital Signal Processors (DSPs) teaching based on an interactive multimedia educational tool, designed with Shockwave ${ }^{\mathrm{TM}}$ and Macromedia Director ${ }^{\mathrm{TM}}$. The use and utility of the tool has been analyzed, and the benefits of this novel teaching methodology have been pointed out. (c) 2007 Wiley Periodicals, Inc. Comput Appl Eng Educ 15: 88-98, 2007; Published online in Wiley InterScience (www.interscience.wiley.com); DOI $10.1002 /$ cae. 20110
\end{abstract}

Keywords: multimedia; interactive learning environments; distributed learning environments; multimedia/hypermedia systems

\section{INTRODUCTION}

In recent years there have been important changes in engineering education, especially in electrical and computer engineering (ECE) education, both in terms of content (curriculum) and what it is taught or how it is taught (delivery of material) [1-6].

On the one hand, emphasis in the electrical engineering field has shifted significantly to the design of digital systems. On the other hand, technology that is around everything we do, has taken a place in the classroom. Since the early days of computers, learning through computer-based environments (hypermedia tools, web-based educational support,

Correspondence to S. L. Toral (toral@esi.us.es). simulation environments, etc.) has dramatically increased [7-13].

In this context, Telecommunication Engineering Studies at the University of Seville was first organized in 1991. The Digital Signal Processor (DSP) course is an intermediate undergraduate digital electronic subject based on the design of advanced embedded digital systems and DSPs. The lack of enough lab work in the original organization motivated a change in the studies in 1998, searching for an increment in the practical work. This fact, together with the necessity of improving the teaching methodology in classrooms with more than 300 students per year, was the starting point to develop new teaching methods using computer-based educational tools [14]. In this task, we have also taken into account the new European Area for Higher Education and ECTS (European Credit Transfer System), which will 
shortly modify the teaching and learning processes $[15,16]$. The creation of this new area supposes a complete turnabout in the teaching and learning processes. Until now, these processes have been driven by the teaching activity, adapting the learning processes to the lecturer profile. But in the near future, the teaching and learning processes will be focused on the learning activity and on the learner profile. As a consequence, it is necessary to know the learner preferences and the variables with a significant relevance in the learner behavior.

\section{Course Description}

The course has been used to teach advanced microprocessors architecture connecting hardware concepts with software, and theoretical knowledge related with Digital Signal Processing. We have chosen a DSP, Texas Instruments $\mathrm{C} 3 \mathrm{x}$ family, as an example of microprocessor architecture to fully accomplish the objectives of the course; the internal structure of $\mathrm{C} 3 \mathrm{x}$ family is used to explain complex embedded systems and its utility in telecommunication area. The TMS320C3X family is a 32 bits floating point general-purpose DSP from Texas Instruments (Dallas; http://www.ti.com). The family architecture features present a central processing module which appears in all family members, and it has been designed to execute commonly used digital signal processing benchmarks with a minimum time load for single-multiplier architecture. These DSPs optimize speed implementing functions in hardware, whereas other processors implement them through software or microcodes, performing parallel multiply and ALU operations on integer or floating-point data in a single cycle. Each processor also possesses a generalpurpose register file, a program cache, dedicated ARAUs, internal dual-access memories, one DMA channel supporting concurrent I/O, and a short machine-cycle time. General-purpose applications are greatly enhanced by the large addresses space, multiprocessor interface, internally and externally generated wait states, two external interface ports, two timers, serial ports, and multiple interrupt structure.

According to our practical experience, DSP teaching may be successfully improved using new computer-based educational tools. Instead of designing and developing this tool without any information about the learner necessities, we have followed a scientific method to design and validate the proposed tool. The scheme is as follows: first, the desirable characteristics of a multimedia system are described. Following these generic guidelines, the description of the content of the tool is detailed in the next section, devoting particular attention to the interactive features and their impact in the learning process. Then, the analysis of the compiled data about the use of the tool is presented, discussing their main implications. Finally, some conclusions are drawn.

\section{INTERACTIVE FEATURES OF MULTIMEDIA SYSTEMS}

Multimedia applications represent the best application of modern technology to education and training in all areas. It can be very cost-effective and increase retention rates dramatically [17]. Multimedia has the potential to create high quality learning environments. The key elements of multiple media, user control over the delivery of information, and interactivity can be used to enhance the learning process through creating integrated learning environments [18]. Explanation can be combined with illustrative examples, online assessment with feedback, and the user can be provided with opportunities to practice and experiment. A range of media elements can be used to convey a given message and the user can study at a time and place convenient to them, taking as long or as little as they need.

There have been many different descriptions and interpretations of interactivity as a concept. Traditionally, interactivity is generally assumed to be a face-to-face communication and learning in a classroom-type environment [19]. Within the context of communication technologies, interactivity can be defined as the degree to which technology supports/ enables interaction resembling human conversation and interpreted as the degree to which a system exhibits first-personness [20]. The three interactive aspects of first-personness are:

- The interactive frequency or the measure of how often a user input is enabled.

- The range of choices available to a user at a given moment during the interaction (for instance, binary choice, e.g., yes/no, has a very narrow range).

- The interactive significance or the measure of the impact of a user's choices and actions upon the outcome/experience of an interactive session.

It has been posited that an instructional system offering greater frequency of interaction and wider range of choices will more actively engage the learner during the session, and, to the extent that the system clarifies the link between their choice and the consequent outcome, motivate the learner to perform better. 


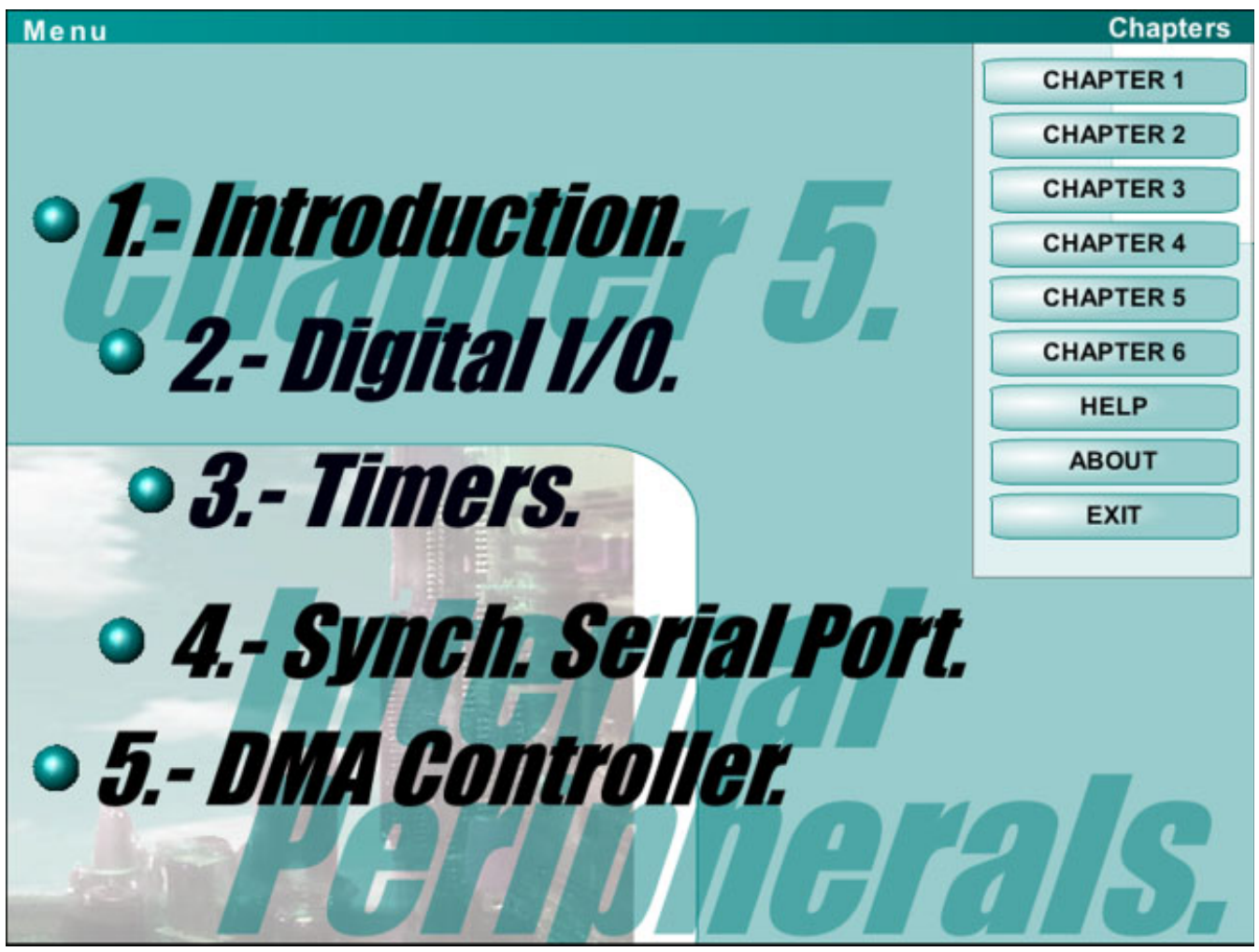

Figure 1 Accessibility of each chapter using the menu option. [Color figure can be viewed in the online issue, which is available at www.interscience.wiley.com.]

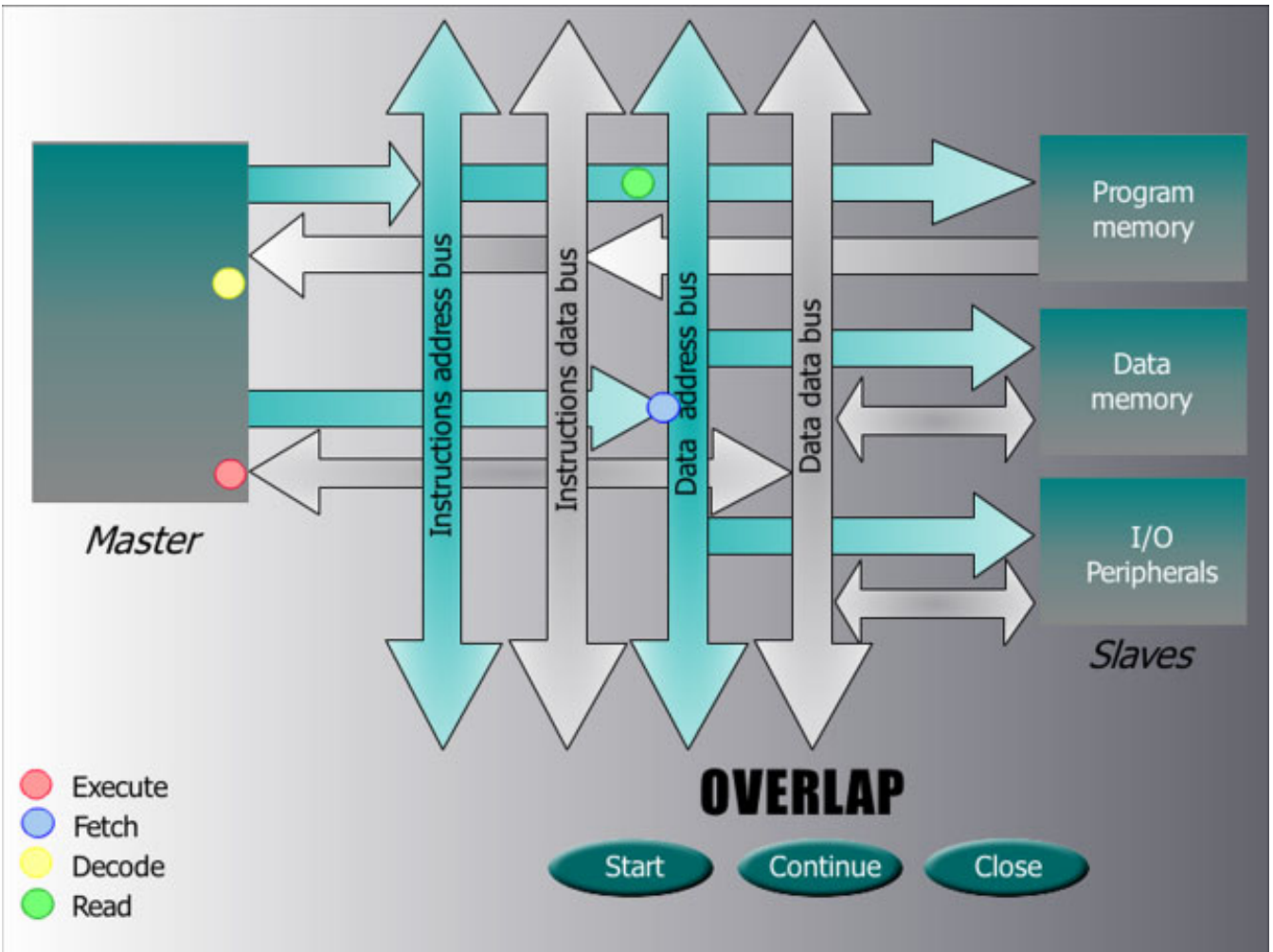

Figure 2 Harvard architecture simulation. [Color figure can be viewed in the online issue, which is available at www.interscience.wiley.com.] 
Weller [21] defines interactivity as a characteristic which allows learners to adjust the instruction to conform to their needs and capabilities; here, the learner becomes an active participant making significant decisions. There are a number of features of learner control, the most common being the control of instructional pace and sequencing/branching. For instance, systems offering learners the ability to control the sequence of the instructional material and set the pace will allow them the freedom to assign appropriate amount of time to each learning module, review, and, when necessary, repeat certain modules. Interactivity, incorporating learner control combined with suitable feedback, can therefore instill and reinforce positive attitude, and enhance performance [22].

However, the very richness and complexity of interactive multimedia can lead to problems if the needs of the learner are not given careful considera- tion. For any design to be successful, in terms of developing usable and understandable products, then that design must be based on the needs and interests of the users, and should be informed by an understanding of their limitations and capabilities. For this reason, we will describe the content of the interactive multimedia tool and then, we will extract their main features according to the users' needs and opinions in the assessment data section.

\section{CONTENT OVERVIEW}

The multimedia content of the website has been designed using the Macromedia ${ }^{\mathrm{TM}}$ Director software. It can be used in traditional classrooms and for asynchronous and non-eyewitness active self-learning to engage students in active reinforcement of the concepts acquired in class.

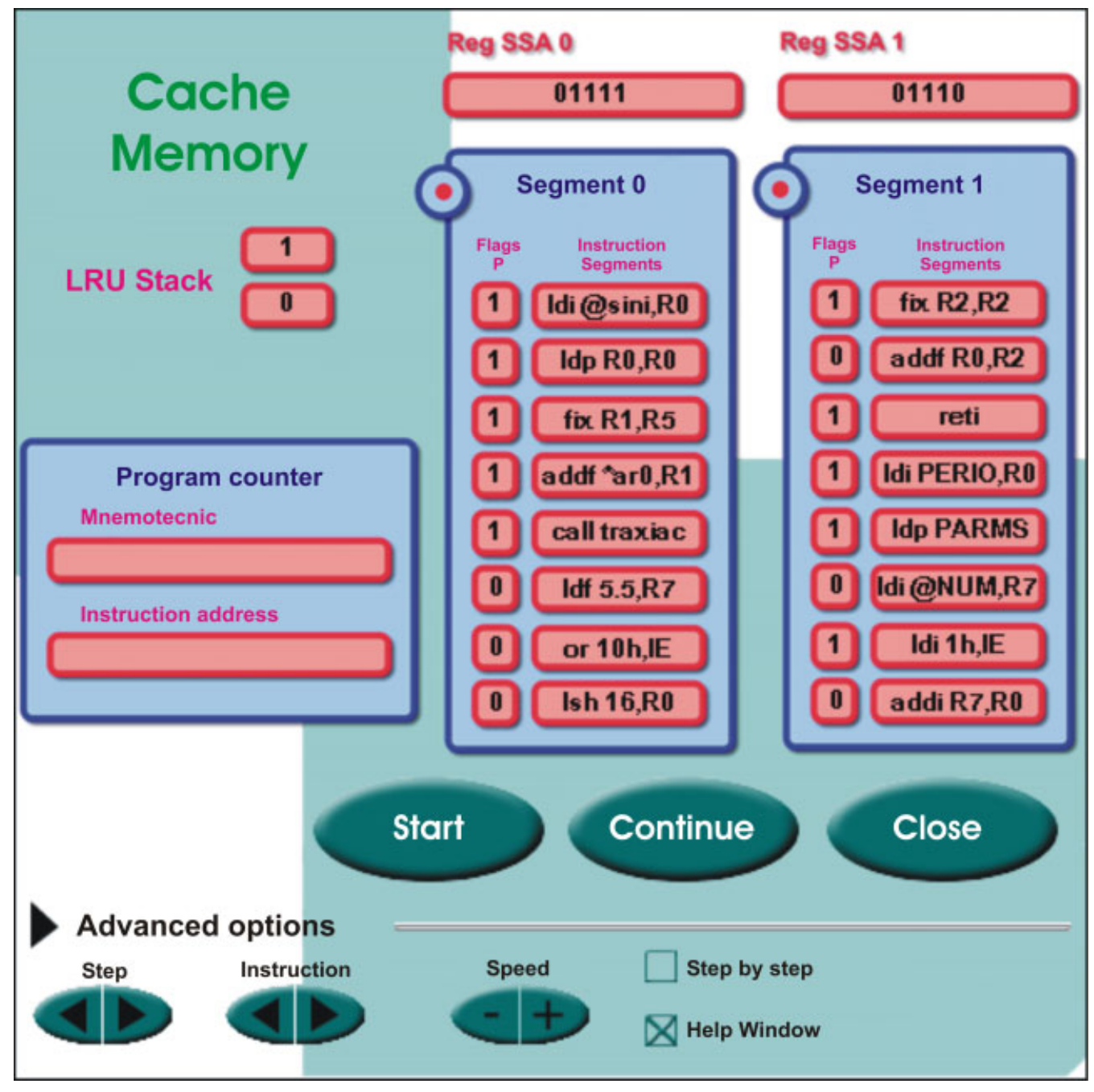

Figure 3 Cache memory simulation. [Color figure can be viewed in the online issue, which is available at www.interscience.wiley.com.] 
Two learning units have been designed. The first one is dedicated to the theoretical teaching and the second one is related to practical exercises and lab work carried out during the academic year. User control is guaranteed by the quick accessibility to each unit using a menu option (see Fig. 1).

The theoretical unit consists on four topics, including a generic embedded systems introduction.

1. An introduction to the DSP devices concepts and their main applications.

2. Basic hardware concepts of TMS320C $3 \mathrm{X}$ devices: CPU and internal bus operations, memory organization, and external bus timing access.

3. Basic software concepts of TMS320C3X devices: data format, addressing modes, and basic assembler instructions.

4. Internal peripheral: timers, serial interfaces, and DMA.

The practical unit is based on nine topics which include the necessary didactic material for the imple- mentation of four lab exercises using a DSP starter kit (DSK30 platform). The content of this unit is organized in the following way:

- Presentation of different DSP applications; implementation of audio signal processing techniques, digital wave generators and FIR or IIR filters.

- Some tutorials: assembler instructions and addressing modes, description of program architecture, DSK30 functionality and characteristics.

- Finally, there are two databases which allow easy access to CPU instruction and internal DSP registers description, and a student auto-evaluation tool.

The main differences between this tool and PowerPoint's presentations are the notion of user control and interactivity. The proposed tool is not a succession of slides, but a real multimedia system in which the user can both modify the navigation through the tool and simulate, with more or less interaction, several features related to DSP teaching

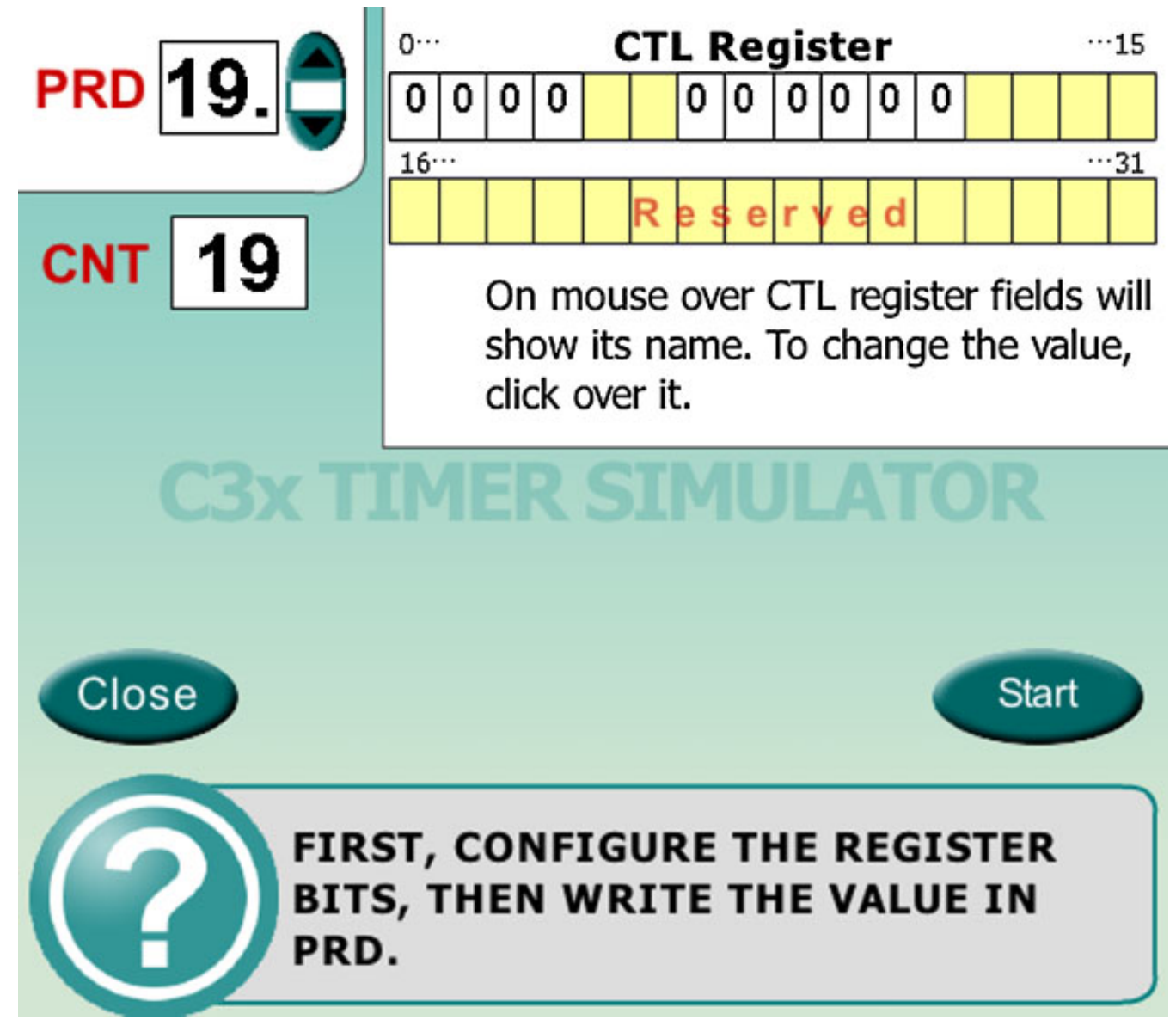

Figure 4 Timer simulation. [Color figure can be viewed in the online issue, which is available at www.interscience.wiley.com.] 
that are difficult to explain in a static slide. This is the case of the Harvard architecture, the cache memory operation or the internal peripheral descriptions.

- Figure 2 shows a shot of the simulation of the Harvard architecture. It is a clear example where a simulation can improve the explanation of some DSP features. Harvard architecture is a way of improving microprocessor speed increasing the degree of parallelism. It is very difficult to show this parallelism using static presentations, because several issues are happening at the same time. But the simulation of Figure 2 shows, using balls of different colors, all the events which are taking place in a certain moment. Each ball represents one instruction. Through this simulation, up to four instructions are being executed, but in different stages of execution. The legends on the left bottom corner of the screen are continuously updated, showing the current stage of each instruction. The three buttons on the bottom, Begin, Continue/Stop, and Close, allow a high degree of control of the simulation.

- Figure 3 is the cache memory simulation. A block of assembler code is executed and, simu- ltaneously, the cache memory is updated. The user can control the execution of the simulation, with the possibility of doing a continuous simulation (with a controllable speed), an instructionby-instruction simulation, or a step-by-step simulation. A help window may be opened to obtain a detailed description of the last action performed.

- Finally, Figure 4 illustrates the timer simulation window. The user can configure the value of the Period Register (PRD) and the value of each bit of the Control Register (CTL). Using the start button, a waveform corresponding to the timer configuration is displayed. This simulator allows the user to identify the mission of the bits of the CTL as well as the response of the timer, according to the established values.

Two databases are available: the instruction database and the register addressing mode database (Figs. 5 and 6, respectively):

- The instruction database contains three fields: syntax, description of the instruction, and an application example.

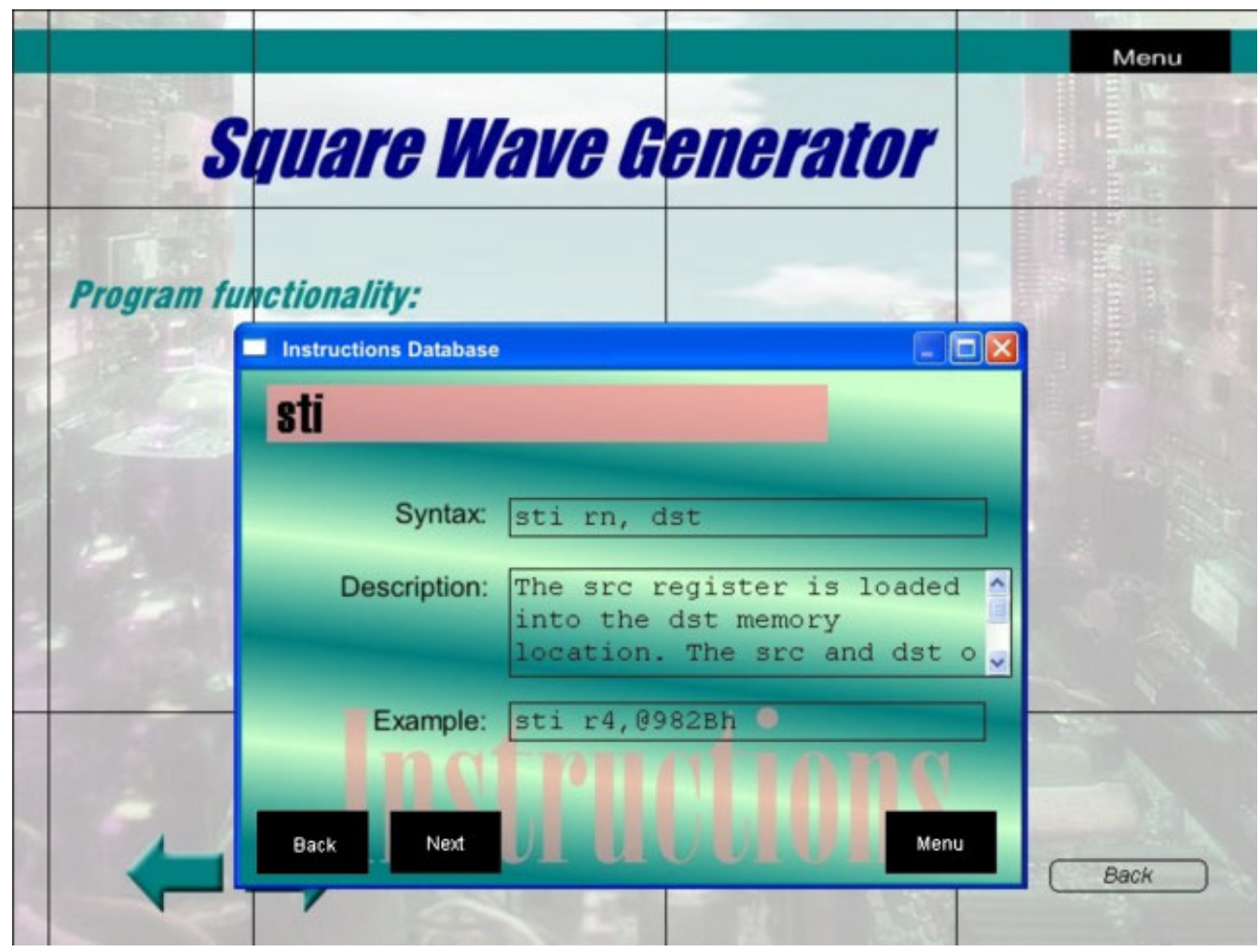

Figure 5 Instruction database. [Color figure can be viewed in the online issue, which is available at www.interscience.wiley.com.] 


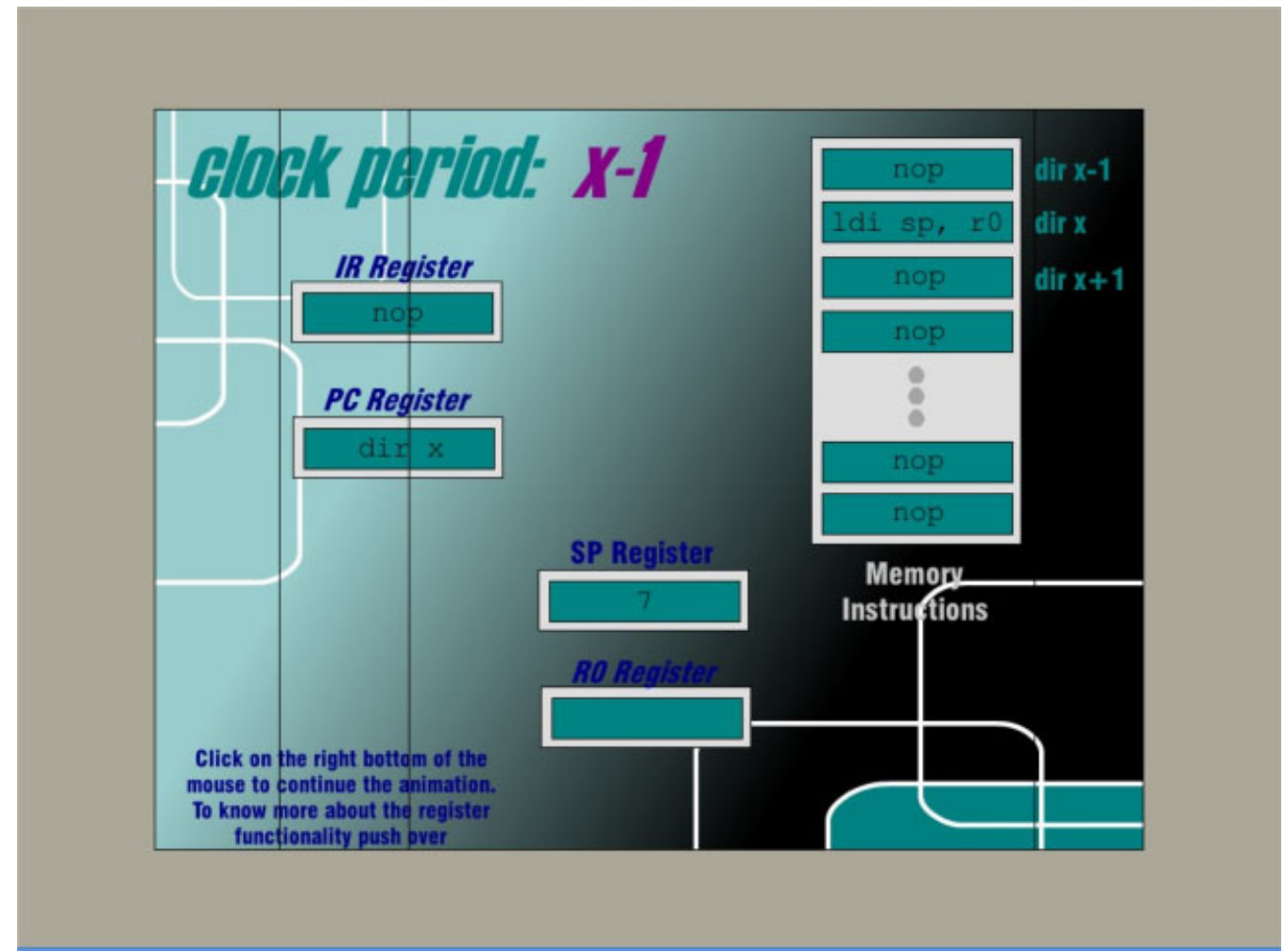

Figure 6 Register addressing mode database. [Color figure can be viewed in the online issue, which is available at www.interscience.wiley.com.]

- The addressing mode database contains a simulation for each addressing mode.

These tools are extremely useful because both of them can be called at any time, for instance, when the user is programming some examples.

\section{ASSESSMENT DATA}

The objective of this section consists on extracting the most interesting contents of the multimedia tool from the learner's point of view. With this aim in mind, a questionnaire has been distributed among 114 students (the technical chart of the statistical study is detailed in Table 1). This questionnaire (Table 2) lists the different topics of the tool in 34 items which summarize the tool content. The first 20 items are related to the theoretical content of the tool (items T01-T20) while the last 14 items are related to the practical content (items P01-P14). Students who have attended the DSP course are requested to mark those items which they have consulted during the DSP course. The mean value of the current use of each item is detailed in the third column of Table 2 .

Table 1 Technical Chart of the Study

\begin{tabular}{|c|c|}
\hline Universe & Students with personal experience with the tool \\
\hline Information gathering method & Personal survey \\
\hline Sample unit & Students who has attended the DSP course \\
\hline Population census & 155 \\
\hline Sample size & 142 \\
\hline Sample error & $3.15 \%$ \\
\hline Reliability level & $99 \%, Z=2.58, p=q=0.5$ \\
\hline Sample procedure & $\begin{array}{l}\text { The survey was directed to the totally of the student attending } \\
\text { the DSP course }\end{array}$ \\
\hline Date of the field study & The survey was carried out in May, 2004 \\
\hline
\end{tabular}


Table 2 Items That Summarize the Tool Content

\begin{tabular}{|c|c|c|}
\hline Item & Content description & Mean value \\
\hline T01 & Introduction to microprocessors & 0.2632 \\
\hline T02 & Differences between microcontrollers and DSPs & 0.3860 \\
\hline T03 & Differences between Von-Neumann and Harvard architectures & 0.5263 \\
\hline T04 & Differences among the elements of the TMS320C $3 x$ family & 0.5000 \\
\hline T05 & The CPU of the TMS320C3x family & 0.4561 \\
\hline T06 & Pipeline execution in the TMS320C $3 x$ family & 0.4737 \\
\hline T07 & Conflicts associated to the pipeline execution & 0.3596 \\
\hline T08 & TMS320C3x memory map & 0.3070 \\
\hline T09 & TMS320C3x CPU interrupts & 0.3509 \\
\hline $\mathrm{T} 10$ & TMS320C $3 x$ cache memory & 0.4561 \\
\hline T11 & TMS320C3x boot-loader & 0.3684 \\
\hline $\mathrm{T} 12$ & Bus external operations: wait states & 0.4123 \\
\hline T13 & Float and integer data format in the TMS320C $3 x$ family & 0.4474 \\
\hline T14 & TMS320C $3 \mathrm{x}$ addressing mode database & 0.5877 \\
\hline T15 & The stack & 0.3070 \\
\hline T16 & TMS320C $3 \mathrm{x}$ instruction set database & 0.5175 \\
\hline T17 & Digital I/0 of the TMS320C3x family & 0.3860 \\
\hline $\mathrm{T} 18$ & Timers of the TMS320C $3 x$ family & 0.4386 \\
\hline T19 & Synchronous serial port of the TMS320C $3 x$ family & 0.4649 \\
\hline $\mathrm{T} 20$ & DMA of the TMS320C3x family & 0.4123 \\
\hline $\mathrm{P} 01$ & Basic instruction examples & 0.5088 \\
\hline $\mathrm{P} 02$ & Assembler directives & 0.5000 \\
\hline $\mathrm{P} 03$ & Two and three operands instructions overview & 0.4912 \\
\hline P04 & Flow control instructions & 0.3860 \\
\hline $\mathrm{P} 05$ & Subroutine call instructions & 0.3684 \\
\hline P06 & Voice acquisition exercise with DSK30 system & 0.5263 \\
\hline P07 & DSK30 hardware overview & 0.4474 \\
\hline P08 & Conditional instructions: condition codes & 0.4035 \\
\hline P09 & Wave generator exercise with DSK30 system & 0.5000 \\
\hline P10 & Delayed branch instructions & 0.3860 \\
\hline P11 & Repeat instructions & 0.4211 \\
\hline $\mathrm{P} 12$ & Parallel execution instructions & 0.5351 \\
\hline $\mathrm{P} 13$ & Digital filter exercise with DSK30 system & 0.5351 \\
\hline P14 & Test quiz & 0.4649 \\
\hline
\end{tabular}

According to the shown results, the most visited contents of the multimedia tool (those which have been consulted by more than $50 \%$ of students) are:

- T14: Addressing mode database.

- P13: Digital filter implementation exercise with DSK30 system.

- P12: Parallel execution instructions.

- P06: Voice acquisition exercise with DSK30.

- T03: Differences between Von-Neumann and Harvard architecture.

- T16: Instruction database.

- P01: Basic instructions examples.

It is worth mentioning that five of the seven most visited contents of the multimedia tool are related to some kind of interactivity. T14 and T16 are the two databases included in the CD-ROM. Both of them have been demonstrated to be very useful as an enquiry service during DSP programming. P12, T03, and P01 include some kind of interactive simulation. The case of T03 was explained in the previous section. Respect to P12 and P01, the CD-ROM includes some dynamic simulations for instruction explanation. Finally, the remainder of the items, P13 and P06 are related to the practical task that students are requested to do at the end of the DSP course. The high value obtained in these items was expected, as students were going to be evaluated in this practical task.

The compiled data can also be used to categorize the contents of the tool. For this purpose, a cluster analysis has been performed [23]. The obtained dendrogram is illustrated in Figure 7. In this figure, the numbers along the horizontal axis represent the items from Table 2 (they have been numbered from 1 to 34 , to leave more space in the horizontal axe), and 


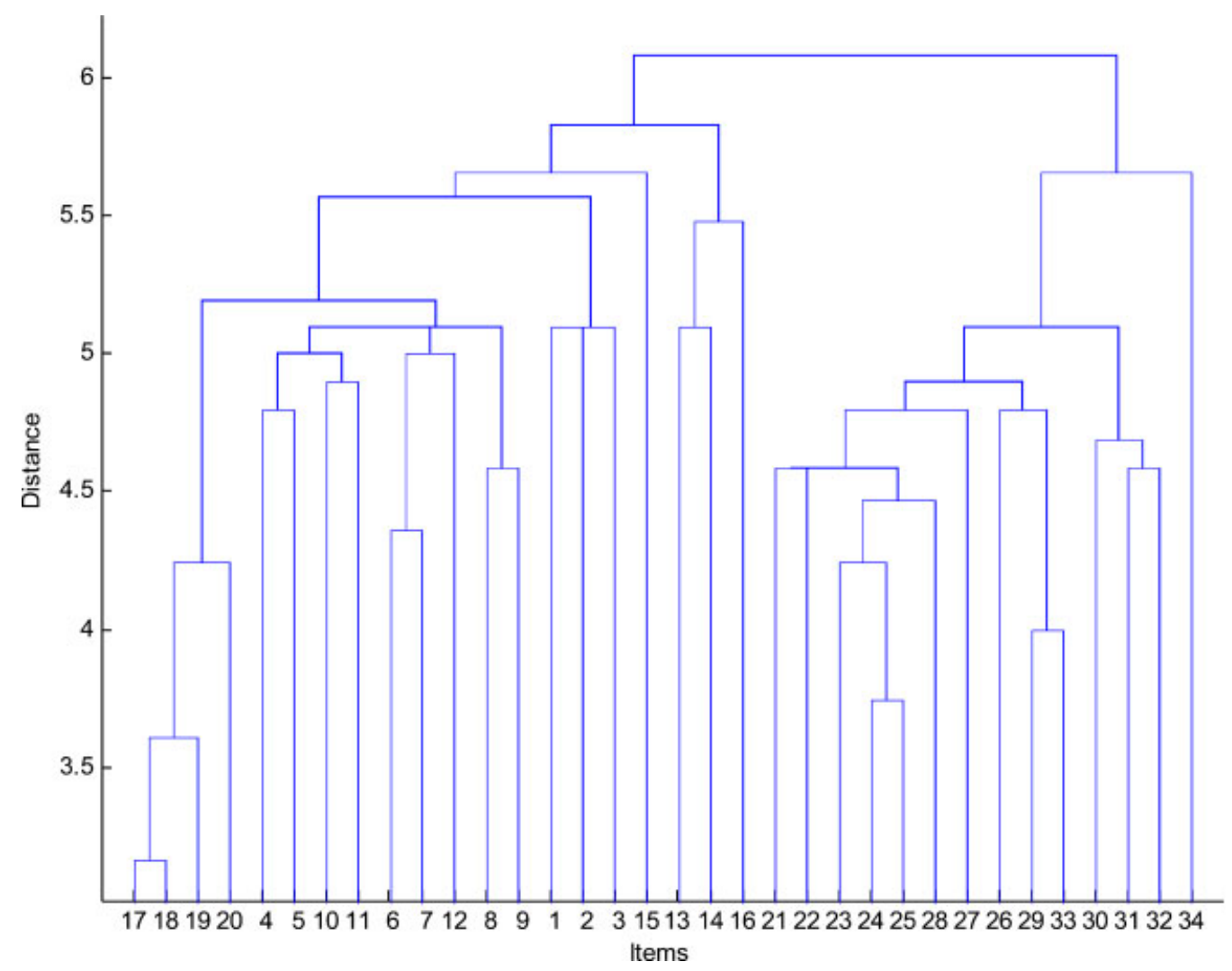

Figure 7 Cluster analysis dendrogram. [Color figure can be viewed in the online issue, which is available at www.interscience.wiley.com.]

the links between them are represented as upside down $U$-shaped lines. The height of the $U$ indicates the distance between the objects.

One way to determine the natural cluster divisions in a data set is to compare the height of each link in a cluster tree with the heights of neighboring links below it in the tree. If a link is approximately the same height as neighboring links, it indicates that there are similarities between the objects joined at this level of the hierarchy. These links are said to exhibit a high level of consistency. If the height of a link differs from neighboring links, it indicates that there are dissimilarities between the objects at this level in the cluster tree. This link is said to be inconsistent with the links around it. In cluster analysis, inconsistent links can indicate the border of a natural division in a data set. The relative consistency of each link in a hierarchical cluster tree can be quantified and expressed as the inconsistency coefficient. This value compares the height of a link in a cluster hierarchy with the average height of neighboring links. If the object is consistent with those around it, it will have a low inconsistency coefficient. If the object is inconsistent with those around it, it will have a higher inconsistency coefficient. The objects at the bottom of the cluster tree, called leaf nodes, which have no further objects below them, have an inconsistency coefficient of zero.

The inconsistency coefficient of the links in the cluster tree can identify the natural divisions in the data set. Specifying an inconsistency coefficient threshold of 0.9 , the original items can be grouped under the 12 categories of Table 3 . They specify a categorization of the contents related to DSP teaching. As a consequence, they can be used as a sort of index of the proposed tool. Table 4 summarizes the obtained result. The third column represents the average mean value of the use associated to each cluster and the fourth column is the relative importance of each cluster. Lab exercises and the special features of TMS320C3x family are the topics that should be covered in full detail, while the stack and the memory map are just the opposite.

\section{CONCLUSIONS}

We have presented a web-based educational tool, designed with Shockwave ${ }^{\mathrm{TM}}$ and Macromedia Director ${ }^{\mathrm{TM}}$, as a teaching methodology in an Undergraduate 
Table 3 Categorization of the Items That Summarize the Tool Content

Categorization of the items according to the cluster No. analysis

1 P01: Basic instruction examples

P02: Assembler directives

P03: Two and three operands instructions overview

P04: Flow control instructions

P05: Subroutine call instructions

P07: DSK30 hardware overview

P08: Conditional instructions: condition codes

2 T04: Differences among the elements of the TMS320C3x family

T05: The CPU of the TMS320C3x family

3 T01: Introduction to microprocessors

T02: Differences between microcontrollers and DSPs

T03: Differences between Von-Neumann and Harvard architectures

4 P06: Voice acquisition exercise with DSK30 system P09: Wave generator exercise with DSK30 system

P13: Digital filter exercise with DSK30 system

5 T10: TMS320C $3 \mathrm{x}$ cache memory

T11: TMS320C3x boot-loader

6 T06: Pipeline execution in the TMS320C3x family

T07: Conflicts associated to the pipeline execution

T12: Bus external operations: wait states

7 T08: TMS320C3x memory map

T09: TMS320C3x CPU interrupts

8 P10: Delayed branch instructions

P11: Repeat instructions

P12: Parallel execution instructions

9 T17: Digital I/0 of the TMS320C3x family

T18: Timers of the TMS320C3x family

T19: Synchronous serial port of the TMS320C $3 x$ family

T20: DMA of the TMS320C3x family

10 T15: The stack

11 P14: Test quiz

12 T13: Float and integer data format in the TMS320C3x family

T14: TMS320C3x addressing mode database

T16: TMS320C $3 \mathrm{x}$ instruction set database

course involved with advanced microprocessors architectures and their applications. The tool has been designed taking into account the interactive features of multimedia instruction. The results have been validated in the Assessment Data Section. The most visited contents of the multimedia tool are related to interactivity, as it was previously postulated. The compiled data have also been used to obtain a categorization of the topics that the multimedia tool should cover. Using a cluster analysis, it has been obtained the main topics and the relative weigh of each one. This is very valuable information for
Table 4 Main Categories Related to DSP Teaching

\begin{tabular}{llrr}
\hline Cluster & \multicolumn{1}{c}{ Description } & $\begin{array}{c}\text { Mean } \\
\text { value }\end{array}$ & $\%$ \\
\hline C01 & $\begin{array}{l}\text { Assembler programming } \\
\text { introduction }\end{array}$ & 0.44 & 8.60 \\
& Special characteristics of & 0.48 & 9.27 \\
C02 & TMS320C3x family & & \\
& DSP architectures & 0.39 & 7.60 \\
C03 & Lab exercises & 0.52 & 10.09 \\
C04 & Memory hierarchy & 0.41 & 7.99 \\
C05 & Pipeline & 0.42 & 8.05 \\
C06 & Memory map & 0.33 & 6.46 \\
C07 & Advanced instructions & 0.45 & 8.68 \\
C08 & Peripherals & 0.43 & 8.25 \\
C09 & Stack & 0.31 & 5.95 \\
C10 & Test 11 & 0.46 & 9.01 \\
C12 & Programming databases & 0.52 & 10.04 \\
\hline
\end{tabular}

designing a tool that can answer the necessities and expectations of users.

\section{REFERENCES}

[1] R. M. Felder, G. N. Felder, and J. Dietz, A longitudinal study of engineering students performance and retention v. comparisons with traditionally-taught students, J Eng Educ 98 (1998), 469-480.

[2] L. Carley, P. Khosla, and R. Unetich, Teaching 'Introduction to Electrical and Computer Engineering' in context, Proc IEEE 88 (2000), 8-22.

[3] J. Wilson and W. Jennings, Studio courses: How information technology is changing the way we teach, on campus and off, Proc IEEE 88 (2000), 72-80.

[4] T. Roppel, An interdisciplinary laboratory sequence in electrical and computer engineering: Curriculum design and assessment results, IEEE Trans Educ 43 (2000), 143-152.

[5] J. Milliken and L. P. Barnes, Teaching and technology in higher education: Student perceptions and personal reflections, Comput Educ 39 (2002), 223-235.

[6] R. L. Taylor, D. Heer, and T. S. Fiez, Using an integrated platform for learning to reinvent engineering education, IEEE Trans Educ 46 (2003), 409-419.

[7] S. Bagui, Reasons for increased learning using multimedia, J Educ Multimedia Hypermedia 7 (1998), $3-18$.

[8] P. Aedo et al., Assessing the utility of an interactive electronic book for learning the Pascal language, IEEE Trans Educ 43 (2000), 403-413.

[9] C. Pahl, Managing evolution and change in web-based teaching and learning environments, Comput Educ 40 (2003), 99-114.

[10] S. F. Almeida, R. Piazzalunga, V. G. Ribeiro, M. B. Casemiro, and R. Moreno, Combining interactivity and improved layout while creating educational software for the Web, Comput Educ 40 (2003), 271-284. 
[11] M. J. Metzger, A. J. Flanagina, and L. Zwarun, College student Web use, perceptions of information credibility, and verification behaviour, Comput Educ 41 (2003), 271-290.

[12] G. Conole, M. Dyke, M. Oliver, and J. Seale, Mapping pedagogy and tools for effective learning design, Comput Educ 43 (2004), 17-33.

[13] W. Christian and M. Belloni, Physlets: Teaching physics with interactive curricular material, PrenticeHall, Englewood Cliffs, NJ, 2001.

[14] M. R. Martínez-Torres, F. Barrero, S. L. Toral, and S. Gallardo, A digital signal processing teaching methodology using concept mapping techniques, IEEE Transactions on Education, to appear.

[15] Communiqué of the Conference of Ministers responsible for Higher Education, Realising the European Higher Education Area, Berlin, September 19, 2003.

[16] Joint declaration of the European Ministers of Education, The European Higher Education Area, Bologna, June 19, 1999.

[17] L. R. Chevalier, J. N. Craddock, P. C. Riley, and B. J. Trunk, Interactive multimedia labware for strength of materials laboratory, Comput Appl Eng Educ 8 (2000), 31-37.

\section{BIOGRAPHIES}

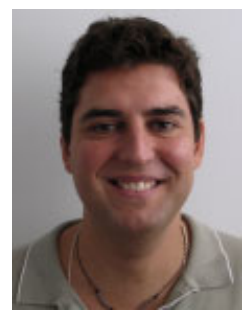

Sergio L. Toral Marín was born in Rabat, Morocco, in 1972. He received the electrical engineering and $\mathrm{PhD}$ degrees from the University of Seville in 1995 and 1999, respectively. He is currently a professor in the Department of Electronic Engineering, Escuela Superior de Ingenieros of Seville. His research interests include microprocessor and DSP devices systems, stochastic processing, and their industrial applications.

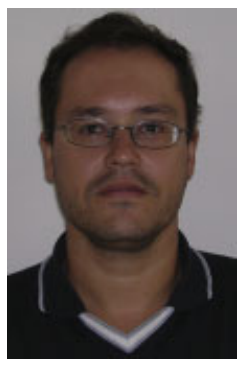

Federico J. Barrero García was born in Seville, Spain, in 1967. He received the electrical engineering and $\mathrm{PhD}$ degrees from the University of Seville in 1992 and 1998 , respectively. In 1992 he joined the Department of Electronic Engineering at the University of Seville, where he is presently a professor. His current interests include microprocessor and DSP devices systems, fuzzy logic-based system, control of electrical drives, and power electronics.
[18] S. Cairncross and M. Mannion, Interactive multimedia and learning: Realizing the benefits, Innov Educ Teach Int 8 (2001), 156-164.

[19] V. Kettanurak, K. Ramamurthy, and W. D. Haseman, User attitude as a mediator of learning performance improvement in an interactive multimedia environment: An empirical investigation of the degree of interactivity and learning styles, Int J Hum Comput Stud 54 (2001), 541-583.

[20] B. K. Laurel, User Centered System Design: New Perspectives on Human-Computer Interaction; In Interface as mimesis, M. A. Donald and D. W. Stephen, Eds., Lawrence Erlbaum, London, 1986.

[21] H. Weller, Interactivity in microcomputer-based instruction: Its essential components and how it can be enhanced, Educ Technol 28 (1988), 23-27.

[22] M. Hannafin and L. Rieber, Psychological foundations of instructional design for emerging computer-based instructional technologies: Part I, Educ Technol Res Dev 37 (1989), 91-114.

[23] S. Z. Selim and M. A. Ismaei, K-means type algorithm: Generalized convergence theorem and characterization of local optimality, IEEE Trans Pattern Anal Machine Intell 6 (1984), 81-87.

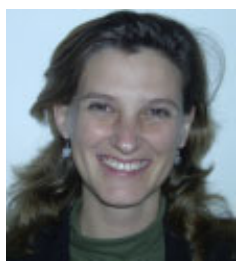

Rocío Martínez Torres was born in Madrid, Spain, in 1973. She received the degree in business administration in 1996 and the PhD degree from the University of Seville, Spain, in 2003. She is currently a professor in the Department of Business Administration and Marketing. Her research interests include intellectual capital and knowledge management.

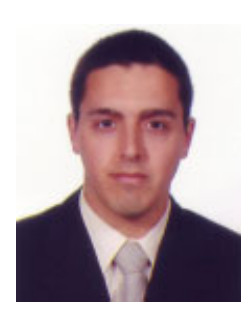

Sergio Gallardo Vázquez was born in Huelva, Spain, in 1978. He received his telecommunication engineering degree in 2002 from the University of Seville, Spain. $\mathrm{He}$ is currently pursuing a $\mathrm{PhD}$ degree in electronic engineering, signal processing, and Communications at the School of Telecommunication Engineering, Seville, Spain. In 2003 he joined the school's Department of Electronic Engineering as a researcher on a project aimed at power electronic conversion control strategies. His research interests include DSP devices system, information and communication technologies, and power electronics. 